ciently great to cause the murmur with the second sound orer the tricuspid valve.

William Riddle, aged 4j, a comb-maker, and an in'veterate spirit-drinker,called on me Fobruary 28, 1843. Hís complexion was sallow and anæmic, and he complained much of palpitation, dyspnœa, and cough. He said his health had been tolerable till five years ago, when he first remarked the palpitation, and observed that it was easily excited by ascending a hill or going upstairs. Twenty years before this he suffered from an attack of acute rheumatism. On listening to the heart, a remarkably loud musical murmur was found to accompany the first sound and was heard very extensively over the chest. He could only lie on his back, and his pulse had a peculiar thrilling character. I saw the man only once at this time, and mide a very brief note of his case.

On March 30, 1S44, he brought an out-patient's re. commendation to the infirmary. His countenance then was bloodless and anxious; there was the same remarkably loud deep-toned and extensively heard musical murmur, loud enough to be distinguished by the unaided ear at a distance of several inches from the chest, and superadded to this older symptom was a friction sound, heard only over the apex of the heart, and at this point only was there tenderness on pressure between the ribs. He was with some diff. culty persuaded to become an in-patient. On examining him in bed, the intensity of the musical sound was found to be greatest over the upper third of the sternum, and over the cartilages of the adjacent ribs on the right side. The musical sound cauld not be heard in the femoral arteries, nor in the abdominal aorta, but it was easily detected in the lower part of the carotids. There was no jugular pulsation. The dulness on percussion over the heart extended beyond the normal limits, and the apex of the heart was felt beating an inch below, and to the ontside of the left nipple.

There was general throbbing of the arteries. The recent attack of partial pericarditis, indicated by the limiled extent of the friction sound, was combatted with leeches, blisters, and calomel; he soon, however, became tired of medicine, and was made an outpatient at his own request on the 1lth of April. The friction sound had nearly disappeared when he left the infirmary, and ten days afterwards it had ceased entirely.

I lost sight of him till the 4th of June, when his wife called at the infirmury to tell me he was much worse. I found him altered in appearance, and wuch thinner; he was greatly harassed by the cough, and expectorated with difficulty a quantity of frothy mucus. He was unable to lie down, and passed the night in a chair; mucous râles were heard extensively over both lungs, and the musical sound was as loud as ever.

On the 13th he was gradually becoming more exhausted, passed restless and sleepless nights, and his legs were codematous. 'There was no trace whatever of the friction sound.

On the 15th a loud and remarkably rough friction ound was heard over the whole of the procordial region, very superficial, and through whicthe murical murmur conld be heard distinctly. The palse 100 and jerking; tenderness on pressure in the intercostal spaces over the heart; cough very distressing and followed by urgent paroxysms of dyspnøa, which was much increased by the supine position. The urine was scanty and high-coloured, and did not coagulate on the application of heat; there was dulness on percussion over the lower part of the right lung, the respiration being indistinctly heard in thatsituation and over the whole of the left lung, and over the remaining portions of the right lung there was large mucous crepitation. Leeches were applied and three grains of calomel were given every two hours.

On the 17th, the friction sound was rather less distinct, and the heart's action irregular and fluttering. On the 18th, the friction sound was less loud and distinct than on the 17th; the breathing, however, had become even more hurried and laboured; he was no longer able to expectorate, the pulse was rapid, the countenance expressed extreme suffering, and he died in the afternoon after a prolonged paroxysm of dyspncea. On opening the chest on the following day a considerable quantity of serum was found in the right pleura, and the surface of the pleura pulmonalis on the right side was to some extent coated with recently effused lymph. The pericardium contained at least a pint of serum. The surfaces of the pericardium were throughout nonadherent, and on both surfaces were found extensive patches of firm, rough, granulated lymph; and which, when rubbed with the finger, gave out a friction sound precisely similar to that heard during life. The heart itself was double the natural size, from dilatation with hypertrophy. The endocardium was throughout considerably injected. The tricuspid valre was perfect, as were also the semilunar valves of the pulmonary artery ; and the only lesion, if lesion it could be called, met with on the right side of the heart, was a somewhat friable state of the chordm tendinea. The pulmonary artery was also softer than natural, and easily broken through by the finger. The mitral valve was healthyperhaps a little thickened. In the aorta immediately above the valves was a considerable atheromatous and bony deposit, the probable cause of the musical murmur; and a similardeposit was found on the aortic valves, but to a much less extent. The bony deposit was confined to an inch and $a$ half of the aorta immediately above the valves, whilst the atheromatous deposit extended along the aorta as far as the finger could be passed into the vessel, but it was felt to diminish in quantity as the distance from the heart increased.

The liver had the nutmeg character, and the kidneys were healthy.

Sheffield, July 3, 1844.

\section{CASE OF IMPERFORATE VAGINA.}

By W. J. SQuare, Esq.,

Surgeon to the Hospital, Plymouth.

Irregular forms of disease occasionally present themselves to the surgeon requiring operation, for the performance of which no exact rules are laid down in the systems of operative surgery.

In these instances the surgeon is obliged to shape out for himself that course of operative proceeding which appears best calculated to fulfil the end required.

The case which I am about to relate is of this nature, 
and is so uncommon as to render it improbable that many instances of like disease can ever fall under the care of one individual. Hence, I conclude that a record of the case is important, as it may form one of a series of similar cases scattered over the pages of medical literature, from the investigation of which the surgeon may deduce useful hints for his guidance.

Mrs. Tremeer, aged 34 years, admitted into the South Devon and East Cornwall Hospital, on the 1st of March, 1843. She is well-formed and of healthy aspect. Three months since she was delivered by the forceps of her first child, after a very protracted and painful labour. Although she suffered from a considerable purulent discharge from the vagina, no suspicion of injury to that canal was entertained until she slept with her husband about six weeks after her accouchement. On examination of the vagina it is found to be quite closed by firm cicatrization, at about an inch from its orifice. The surface of the cicatrization is puckered up like the end of a purse, and about the centre of it is a dimple or depression. The finger in the rectum does not recognize any extensive tract of induration in the vagina.

From this examination, in which I was assisted by my colleagues, Messrs. Derry and Whipple, I concluded that the vagina was not cicatrized from the orifice to the os uteri, but that there must be a cavity, consisting of the upper portion of the vagina beyond the cicatrix. Strongly impresssed with this idea, I pushed a blunt probe ayainst the dimpled part of the cicatrix, and penetrated it, the septum appearing to be about half or three quarters of an inch in thickness.

March 3rd. A wax bougie (urethral) No. 6, passed through the opening made by the probe. No menstrual fluid above the obstruction.

5th. No. 8 urethral bougie passed.

7th. No. 10 ditto passed.

8th. Menstruation established.

10 th to 30th. For the last three weeks I have endeavoured to dilate the cicatrix by bougies and sponge tents; but the attempt has been so painful and inefficacious, that $I$ have given up further attempts at dilatation, and determined to wait for the departure of the next catamenial discharge, and then perform an operation for her relief.

April 20th. A few days since she had pain in her back for some hours, but menstruation has not taken place. Having introduced a female catheter through the opening previously made, no discharge either followed its removal, or was entangled in the eyes of the instrument.

April 22nd. With the advice and concurrence of my colleagues I performed the following operation:-

The patient tied as for lithotomy.

The fore finger of the left hand was introduced within the rectum so as to depress it towards the sacrum. A straight bistoire cachée, set at an inch, was passed through the opening in the cicatrized ragina, and the blade being directed as in the lateral operation of lithotomy, sprung and withdrawn. An immense gush of dark grumous liquid followed this proceeding. The finger now discovered the upper part of the ragina to be dilated into a large oval sac, with a healthy $o$ s uteri at its upper part. The cicatrix was now divided on the right side in the same direction, by a probepointed knife. A large cylinder of oiled lint was introduced within the vagina, and the patient removed to her bed.

Vespere. The plug forced out by ineffectual efforts at micturition. Bladder distended; considerable fever; urine drawn off. Ordered :-

Calomel, four grains; opium, one grain and $d$ half ; at $t^{\prime \prime}$ bed-time. Poultice to the belly. Saline mixture, wit's tincture of henbane.

Plug of lint not re-introduced.

23rd. More comfortable - urine again drawn offplug re-introduced.

24th. A wooden plug introduced within the vagina and retained by a bandage.

May 20th. From time to time there has been some febrile excitensent, with hysteric combination. The wooden plug excites a good deal of purulent discharge. Ordered :-

Compound-alum enema three times daily.

Di-sulphate of quinine . . . 1 scruple.

Diluted sulphuric acid . . 2 drachms.

Water. . . . . . . 12 ounces.

Two table spoonfuls to be taken three times a day. Meat diet, with beer.

June 4th. Discharge much less. Wound red and vascular, not granulated. A gum elustic rectum bougie substituted for the wooden plug, and retained four hours every morning. Walks out of doors.

'July 20th. The same treatment has been steadily pursued. The vagina does not contract. There is searcely any discharge. Health and spirits good. No tamenial discharge appeared.

Angust 20th. Treatment continued to this date. Has had sexual intercourse without much pain ; catamenia absent. Discontinue the injection and quinine; continue the use of the bougie.

September 21st. Has had frequent sexual intercourse, and there is now little or no pain. No discharge; no menstruation.

Norember 1st. The vagina has no tendency to contract. Catamenia absent. Continue the bougie.

Feb. 10, 1844. I heard from a friend of hers that she is quite well, but could obtain no particulars as to menstruation, \&c.

\section{ON PUS-GLOBULES; IN REPLY TO AN AR-} TICLE IN THE BRITISH AND FOREIGN MEDICAL REVIEW.

By W. Adpison, Esq., Malvern.

to THE EDITOR OF THE PROVINCIAL MEDICAL AND SURGICAL JOURNAL.

Sir,

The author of the articles in the British and Foreign Medical Reriew, (April and July,) referring to my Experimental Researches, is, I am aware, considered, and very justly so, as an authority upon matters relating to microscopical investigation, and, therefore, while the subject of nutrition may be still fresh in the recollection of your readers, I am anxious to notice a very important point upon which we are at issue, leaving your readers and the members of our Association to judge between us, after having heard my statement in reply.

I am the more anxions. to do this now, because the reviewer says that " my mode of reasoning, if followed 